This item was submitted to Loughborough's Research Repository by the author.

Items in Figshare are protected by copyright, with all rights reserved, unless otherwise indicated.

\title{
Influence of in-plane dynamics of thin compression rings on friction in internal combustion engines
}

PLEASE CITE THE PUBLISHED VERSION

http://dx.doi.org/10.1115/1.4006690

PUBLISHER

(C) ASME

VERSION

AM (Accepted Manuscript)

LICENCE

CC BY-NC-ND 4.0

\section{REPOSITORY RECORD}

Baker, Christopher E., Stephanos Theodossiades, Homer Rahnejat, and Brian Fitzsimons. 2019. "Influence of In-plane Dynamics of Thin Compression Rings on Friction in Internal Combustion Engines". figshare. https://hdl.handle.net/2134/13351. 
This item was submitted to Loughborough's Institutional Repository (https://dspace.lboro.ac.uk/) by the author and is made available under the following Creative Commons Licence conditions.

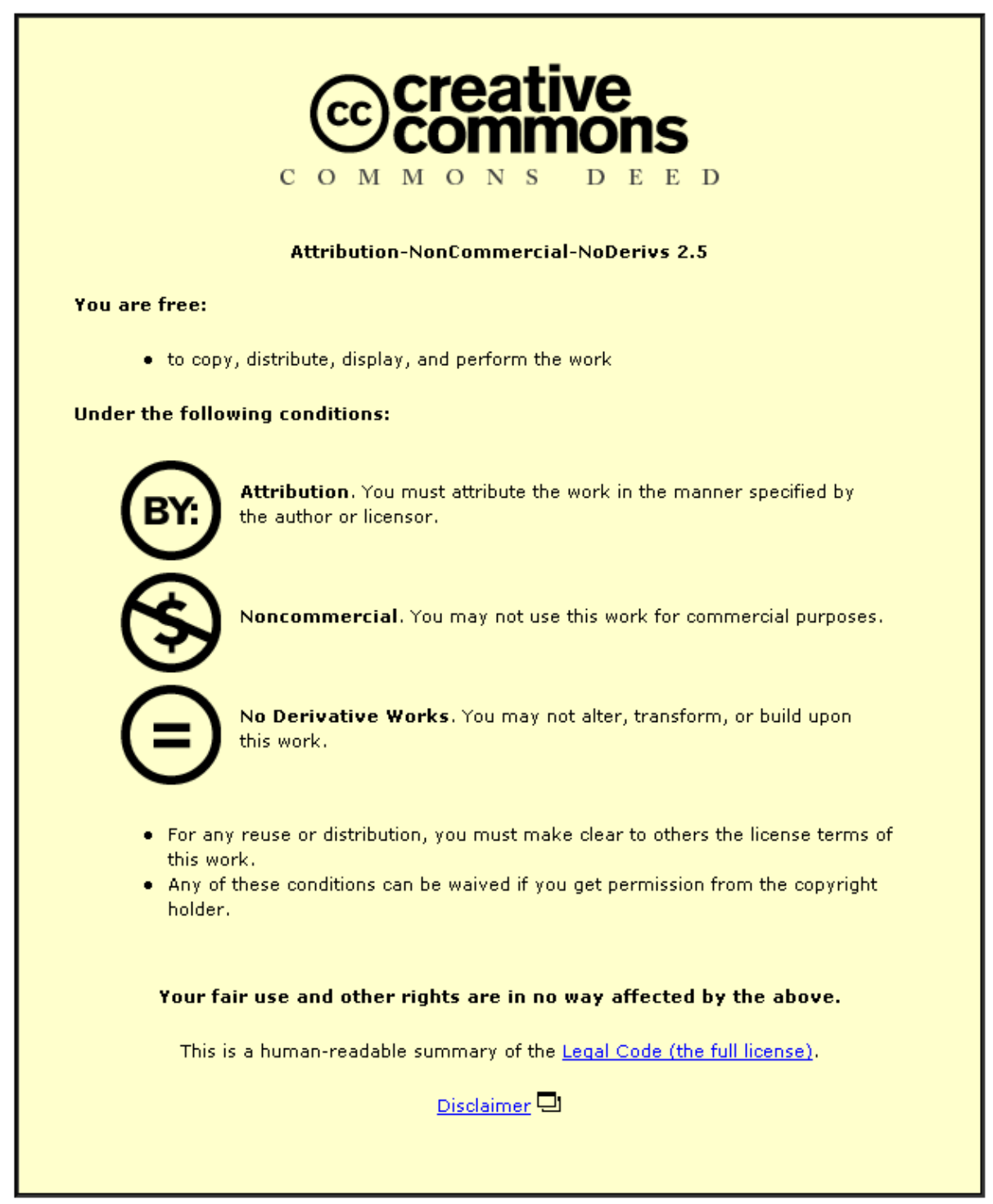

For the full text of this licence, please go to: http://creativecommons.org/licenses/by-nc-nd/2.5/ 


\title{
Influence of In-plane Dynamics of Thin Compression Rings on Friction in Internal Combustion Engines
}

\author{
C.E. Baker", S. Theodossiades ${ }^{1 \#}$, H. Rahnejat" and B. Fitzisimons* \\ \#Wolfson School of Mechanical \& Manufacturing Engineering, \\ Loughborough University, Loughborough, UK \\ *Aston Martin, Gaydon, Warwickshire, UK \\ ${ }^{1}$ Corresponding Author: S.Theodossiades@lboro.ac.uk \\ Tel: + 44 (0) 1509227664 Fax: + 44 (0) 1509227648
}

\begin{abstract}
The compression ring-bore conjunction accounts for significant frictional parasitic losses relative to its size. The prerequisite to improving the tribological performance of this contact is a fundamental understanding of ring dynamics within the prevailing transient nature of regime of lubrication. Studies reported thus far take into account ring-bore conformance, based on static fitment of the ring within an out-of-round bore, whose out-of-circularity is affected by manufacturing processes, surface treatment and assembly. The static fitment analyses presume quasi-static equilibrium between ring tension and gas pressure loading with generated conjunctional pressures. This is an implicit assumption of ring rigidity whilst in situ. The current analysis considers the global modal behaviour of the ring as an eigenvalue problem, thus including its dynamic in-plane behaviour in the tribological study of a mixed-hydrodynamic regime of lubrication. The results show that the contact transit time is shorter than that required for the ring to reach steady state condition. Hence, the conjunction is not only subject to transience on account of changing contact kinematics and varied combustion loading, but also subject to perpetual ring transient dynamics. This renders the ring-bore friction a more complex problem than usually assumed in idealised ring fitment analyses. An interesting finding of the analysis is increased ring-bore clearance at and in the vicinity of top dead centre, which reduces the ring sealing effect and suggests a possible increase in blow-by. The current analysis, integrating ring in-plane modal dynamics and mixed regime of lubrication includes salient features which are closer representation of practice, an approach which has not hitherto been reported in literature.
\end{abstract}




\section{Keywords}

Compression ring, in-plane dynamics, modal response, mixed regime of lubrication

\section{Nomenclature}

$A$ - Cross-sectional area of ring

$A_{a}-$ Asperity contact area of the ring surface

$A_{c}-$ Contact area of ring surface

$A_{n 1}-A_{n 6}-$ Modal function constants

$b$ - Ring facewidth

$C_{n 1}, C_{n 2}$-Time response constants

$d$ - Ring thickness

$d_{n}$ - Modal function constant

$e_{n}-$ Modal function constant

$E$-Young's modulus

$f_{a}$ - Asperity friction force

$F_{e}$ - Ring tension

$F_{g}-$ Applied Gas force

$F_{\text {groove }}-$ Groove friction force

$F_{h}-$ Viscous friction

$F_{R}-$ Net (residual) radial force

$F_{T}$ - Tangential force

$f_{n}$ - Modal function constant

$h$ - Film thickness

I-Second area moment of inertia

$i$ - Mode number (orthogonality condition)

j-Mode number (orthogonality condition)

$m-$ Ring mass per unit length

$p$ - Pressure

$Q_{n}-$ General forcing function

$R_{g}$ - Reaction force of piston groove

$R$ - Ring nominal radius

$s-$ Ring axial profile

$t$-Time
$V$ - Tangential modal response

$v$-Tangential displacement

$W$-Radial modal response

$W_{a}-$ Asperity load

$W_{h}$ - Lubricant reaction

$x-$ Direction of entraining motion

$w$-Radial displacement

$\alpha$ - Incomplete Ring subtended angle

$\Delta$ - Global deformation of ring

$\delta_{n}-$ Modal function constant

$\zeta$ - Asperity distribution per unit area

$\eta$ - Lubricant viscosity

$\kappa$ - Average asperity tip radius

$\lambda_{n}$ - Frequency parameter

$\lambda_{s}-$ Stribeck oil film parameter

$\mu_{n}$ - Modal function constant

$\xi_{n}$ - Time response of ring deflection

$\rho$ - Lubricant density

$\sigma$-Roots of the eigenvalue problem

$\sigma_{R M S}-$ Composite roughness of counterfaces

$\tau-$ Viscous shear stress

$\tau_{0}-$ Eyring shear stress of the lubricant

$\tau^{\prime}$ - Time segment

$\varphi$ - Direction along ring periphery

$\omega_{f}-$ Excitation frequency

$\omega_{n}$ - Natural frequency

Subscripts

$n$-mode shape index 


\section{Introduction}

Between $50-60 \%$ of the input fuel energy in an internal combustion engine is lost through thermal and mechanical losses. With ever increasing costs and scarcity of fossil fuels, in addition to the untoward effects of ensuing emissions, reduction of these losses have become the driving force in a quest for alternative means of propulsion. However, there are significant infrastructural obstacles in the rapid development and implementation of alternatives. As a consequence, it is envisaged that the internal combustion engine would remain an important integral part of any transport solution for the foreseeable future, at least up to 2030 (King, 2007). The causes of engine losses can be categorised as thermodynamic and parasitic. Thermodynamic losses are those which are the result of heat losses in combustion, by conduction through engine surfaces and by lubricant through convection, as well as heat expulsion from the exhaust. Parasitic losses encapsulate the inefficiencies due to moving parts, such as pumping losses, mechanical out-of-balances, noise and vibration, and chiefly friction. These losses account for approximately $20 \%$ of all the engine losses, a significant portion of which (nearly $45 \%$ ) occurs in piston-cylinder system. The compression ring alone can account for $5 \%$ of the total engine losses (Andersson, 1991). This suggests that optimisation of tribological performance of the compression ring conjunction warrants more attention; as such a relatively small component is responsible for a disproportionate level of inefficiency. In particular, due to the prevailing transient conditions the compression ring is subject to significant variable loading and thus undergoes fairly complex motions.

In the assessment of ring-bore tribology, the current literature often does not take into account any ring modal behaviour, instead treating the ring as a rigid body (Priest and Taylor, 2000). This assumption is often used when solving Reynolds equation to predict conjunctional pressures and the corresponding lubricant film thickness. However, global deformation is bound to occur when the thin ring structure is subjected to the forces encountered in a piston cylinder-ring conjunction, particularly at the point of firing (Tian, 2002). The resulting vibratory motions take place in the radial plane of the ring as well as in the out-of-plane direction. The current work investigates the in-plane compression ring dynamics.

Studies on ring dynamics have their roots in the theory for elastic beam and the analysis of curved arches. Lamb (1888) studied the in-plane deformation of a bar of uniform cross-section. Though limited to beams with relatively small curvature, equations of motion for a free bar were derived and solved. Den Hartog (1928) extended this approach, using the Rayleigh-Ritz energy method to derive formulae for the first two natural frequencies of an incomplete circular arc, for both hinged and 
clamped boundary conditions. Lord Rayleigh's method was modified by Brown (1934) in order to find an approximate solution for the in-plane radial vibrations. The numerical results conformed reasonably well to the experimental observations. The Rayleigh-Ritz method was used later to determine the lowest natural frequencies of elastic arcs with and without hinges by Volterra and Morell (1961). The method was applied to both in and out-of-plane motions.

The classical equations of motion for a variety of beams and structures were presented by Love (1944). These included an incomplete ring of slender cross-section, assuming an inextensional ring central radial axis. Morley (1957) investigated the first ten modes of an incomplete thin ring using an exact analytical method. However, no mode shapes were presented for comparative purposes. Later the in-plane inextensional vibration of an incomplete ring was also evaluated by Archer (1960), who focused on rings with relatively slender cross-sections. His study was confined to in-plane excitations and made use of the classical equations of motion presented earlier by Love (1944). Archer's results showed good agreement with those found earlier by Den Hartog (1928), with similar mode shapes.

Ojalvo (1962) stated that treating the in-plane and out-of-plane ring motions as separate problems is a valid assumption, since the two motions are considered as uncoupled. He also neglected the effect of shearing deformation, based on the explanation expounded by Timoshenko (1951) that such an assumption is valid for thin rings. Lang (1962) presented dynamic response solutions for both extensional and inextensional thin circular rings. Antman and Warner (1965) developed an iteration scheme to analyse the coupling effects between ring axial excitation and its in-plane curvature. This method is valid for an extensible neutral axis, with inextensibility resulting in the decoupling of the in and out-of-plane motions, as was initially stated by Ojalvo (1962). Chen (1973) developed an analytical technique for calculating natural frequencies for beams with non-uniform cross-section, as well as varying boundary conditions.

More recently, Gardner and Bert (1984) presented comparison of a numerical method to calculate ring in-plane natural frequencies and mode shapes with experimental data. Auciello and De Rosa (1993) used the assumptions of negligible rotary inertia, inextensible neutral axis and a small crosssection-to-ring radius ratio in order to develop a method for calculating natural frequencies of circular arcs. This method can be extended to the case of rings of varying cross-sections. Kang et al (1995) applied the differential quadrature method (DQM) to calculate the eigenvalues for ring inplane vibration, considering both extensional and inextensional cases. They also applied the same method to out-of-plane ring oscillations. 
Earlier tribological analyses of the piston ring-cylinder liner conjunction invariably assumed isothermal, hydrodynamic conditions before any elastohydrodynamic or mixed regimes of lubrication were taken into account. Dowson et al (1983) stated that hydrodynamic lubrication is usually expected throughout most of the engine cycle. However, around piston reversal points (top and bottom dead centres), EHL or mixed regime of lubrication may be expected (Johnson, 1970). Ma et al (1997) presented an isothermal solution for ring-bore conjunction taking into account mixed and elastohydrodynamic regimes of lubrication and compared their predictions with the experimental data obtained by Hamilton and Moore (1974). There have been other mixed hydrodynamic/elastohydrodynamic solutions, for example by Akalin and Newaz (2001), Bolander et al (2005), D'Agostino and Senatore (2010), Mishra et al $(2008,2009)$ and Spencer et al (2011). These works among others have included various salient features such as bore out-of-roundness, ring-bore conformability, ring and liner topography, as well as the effect of cavitation (Chong et al, 2010). Some authors (Akalin and Newaz, 2001 and Mishra et al, 2009) have shown good agreement with measured friction data, often obtained through use of floating liners under engine motored condition (Furuhama and Sasaki, 1983). However, Ghosh and Gupta (1998) observed significant differences in load-carrying capacity, film thickness and rolling traction at high sliding speeds, when taking into account heat generated in the contact. For a thermal-elastohydrodynamic (TEHD) analysis, combined solution of Reynolds and energy equations is required. Such an approach has been reported by Almqvist and Larsson (2002), but with a ring subject to local deformation only. Knoll et al (1996) developed a computer simulation program in an attempt to find optimum design parameters for the piston, piston rings and cylinder. All three of these components were modelled. However, there was no comparison with the work of others for verification purposes. Piston ring dynamics in a radial direction were also investigated by Piao and Gulwadi (2003). They investigated the effects of an axially distorted bore on the ring dynamics, using the simulation tool RINGPAK. This study assumed a quasi-static force balance, and showed good qualitative comparisons with experimental results. Tian et al (1998) presented a ring dynamics and gas flow model which accounted for a ring pack comprising 3 rings. It focused on the effect of ring flutter and out-of-plane twist.

An analytical solution for in-plane dynamics of compression rings is presented in this paper. An analytical solution has the advantage of being computationally less intensive than a numerical approach and easily integrated within a ring-bore tribological study. Of particular interest is to ascertain the modal behaviour of the ring under transient conditions, experienced through its sliding motion. The analysis shows that contact transit time is shorter than the settling time of the ring dynamic response. This means that a steady state ring modal shape may not be assumed at any 
instantaneous contact time. However, ring in-plane dynamics affects the lubricant film thickness profile and thus the generated friction. There is, therefore, a clear distinction between the ring's steady state forced response and its transient oscillatory response during its sliding motion. Rapidly changing gas pressure and ring sliding velocity promote incessant ring transient behaviour. This is a new finding, indicating that elastic ring behaviour prohibits the assumption of steady state response or quasi-static ring-bore conformability, which is often an underlying assumption in tribological studies.

The structure of paper follows an initial description of ring-bore conjunction, ring in-plane eigenvalue problem and ring modal forced response, the validity of which is ascertained against an FEA model. The interplay between the ring in-plane modal dynamics and the ring-bore transience is investigated. It is shown that the ring response remains in an incessant state of transience. The corresponding lubricant film thickness profiles along the ring perimeter are presented, as well as the generated friction under mixed regime of lubrication.

\section{Methodology}

\section{1- Forces acting on the compression ring}

Piston compression rings are subjected to a number of forces, all of which vary during the engine cycle. These are shown in Figure 1. They include the ring tension (elastic) force, $F_{e}$, which is generated as the result of the fitment of an incomplete circular ring of larger radius than that of the bore. This force strives to return the ring to its original shape, thus exerting a force onto the bore surface. Ring tension is assumed to remain constant for an idealised circular cylindrical bore. Then, there is the gas pressure loading $F_{g}$, which acts behind the ring inner rim, outwards in the same sense as the $F_{e}$. This force varies as the result of varying combustion chamber pressure. The net force acting on the ring-bore contact is therefore the combination of these two forces at any instant of time. In a quasi-static analysis with an assumed rigid ring (as in many reported analyses), this net force is equilibrated by the generated conjunctional pressures. These pressures are as the result of instantaneous tribological condition, which is determined according to the gap between the ring and the bore surface. In general, a mixed elastohydrodynamic analysis is carried out, culminating in contact reactions due to lubricant viscous action, $W_{h}$ and asperity interactions, $W_{a}$. Thus:

$$
W_{h}+W_{a}=F_{e}+F_{g}
$$




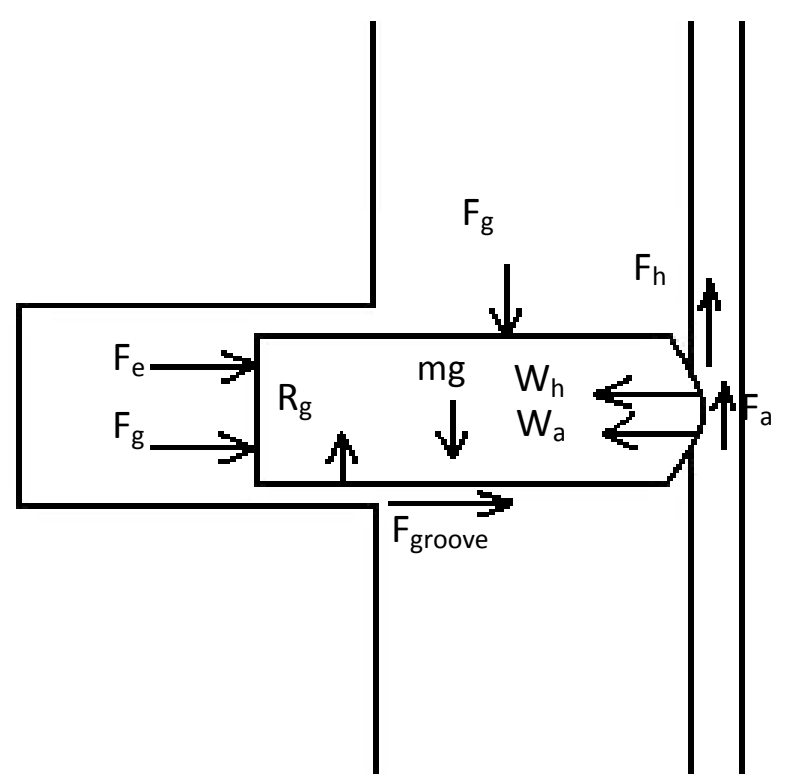

Figure 1: Cross-sectional free body diagram of the compression ring-cylinder liner conjunction

\section{2- Ring-bore conjunction}

The viscous reaction is obtained as: $W_{h}=\iint p_{h} d x d \varphi$, where the pressures $p$ are obtained through simultaneous solution of Reynolds and film thickness equations in the usual manner (Mishra et al, 2008, Baker et al, 2011). The current analysis assumes no side-leakage flow in the direction of ring periphery. Thus:

$$
\frac{\partial}{\partial x}\left[\left(\frac{\rho h^{3}}{6 \eta}\right) \frac{\partial p_{h}}{\partial x}\right]+\frac{1}{R^{2}} \frac{\partial}{\partial \varphi}\left[\left(\frac{\rho h^{3}}{6 \eta}\right) \frac{\partial p_{h}}{\partial \varphi}\right]=\Delta U \frac{\partial}{\partial x}(\rho h)+2 \frac{\partial}{\partial t}(\rho h)
$$

and

$$
h(\varphi, t)=h_{m}(t)+s(x)+\Delta(\varphi, t)
$$

A parabolic ring face-width profile $s(x)=\frac{x^{2}}{2 R_{e}}$ is assumed. Furthermore, as shown by Ma et al (1997), Mishra et al (2008) and D'Agostino and Senatore (2010) the generated pressures are insufficient to cause either localised deflection of the ring or piezo-viscous action of the lubricant (elastohydrodynamics). When the film thickness is insufficient to guard against boundary interaction of surfaces (i.e. $\lambda_{S}=\frac{h}{\sigma_{R M S}}<3$, where $\sigma_{R M S}$ is the combined root mean square roughness of the ring and bore counterfaces), then some of the load is carried by the contact of opposing asperity pairs. Asperity pressure is obtained as (Greenwood and Tripp, 1971):

$$
P_{a}=\frac{8 \sqrt{2}}{15} \pi\left(\zeta \kappa \sigma_{R M S}\right)^{2} \sqrt{\frac{\sigma_{R M S}}{\kappa}} E^{*} F_{5 / 2}\left(\lambda_{s}\right)
$$


$F_{5 / 2}\left(\lambda_{s}\right)$ is a statistical function assuming a Gaussian distribution of asperities on the contiguous contacting surfaces (Teodorescu et al, 2005), and the boundary reaction for an assumed conforming ring-bore contact becomes:

$$
W_{a}=\int_{0}^{\alpha} \int_{0}^{b} P_{a} d x d y
$$

\section{3- Ring elastic response}

Equation (1) can now be used as a constraint function in the form of a convergence criterion for a rigid ring, where $\Delta(\varphi)=0$ in equation (3):

$$
\operatorname{Err}_{\text {load }}=\frac{\left|\left(F_{e}+F_{g}\right)-\left(W_{h}+W_{a}\right)\right|}{\left(F_{e}+F_{g}\right)} \leq 1 \times 10^{-3}
$$

However, for an elastic ring, its global deformation, $\Delta(\varphi)$ at any instance of time is as the result of the residual balance of forces (net force) acting upon it. Hence, quasi-static balance (equation (6)) may not be assumed. Thus, at any instant of time during the engine cycle:

$$
F_{R}=\left(F_{e}+F_{g}\right)-\left(W_{h}+W_{a}\right)
$$

In practice, this residual radial force causes in-plane ring inertial dynamics as well as inducing ring modal behaviour. Assuming the former to be negligible due to good ring-bore conformance, the effect of the net force translates to global modal deformation of the in situ ring $\Delta(\varphi)$ as an eigenvalue problem. Once this global shape of the ring is obtained, the film thickness in equation (3) is adjusted and new hydrodynamic pressures are calculated through Reynolds equation, and thus the new values for $W_{h}$ and $W_{a}$ at any crank-angle position of the ring.

Solutions for a ring-bore conjunction under mixed regime of lubrication, in accord with equation (1) have been reported by Ma et al (1997), Bolander et al (2005) and Mishra et al (2008). Hitherto, no solution of ring-bore tribology, taking into account the transient ring modal dynamics has been reported.

Since the gas pressure acting on the ring varies with crank angle, the net excitation force, $F_{R}$ is variable. Therefore, the elastic behaviour of the ring is transient. In the current analysis, the compression ring is assumed to be an incomplete circular arc of rectangular cross-section. Figure 
2(a) shows the radial, $w$ and tangential, $v$ degrees of freedom, whilst figure 2(b) shows the forces and moments acting upon a small cross-sectional segment of the ring:
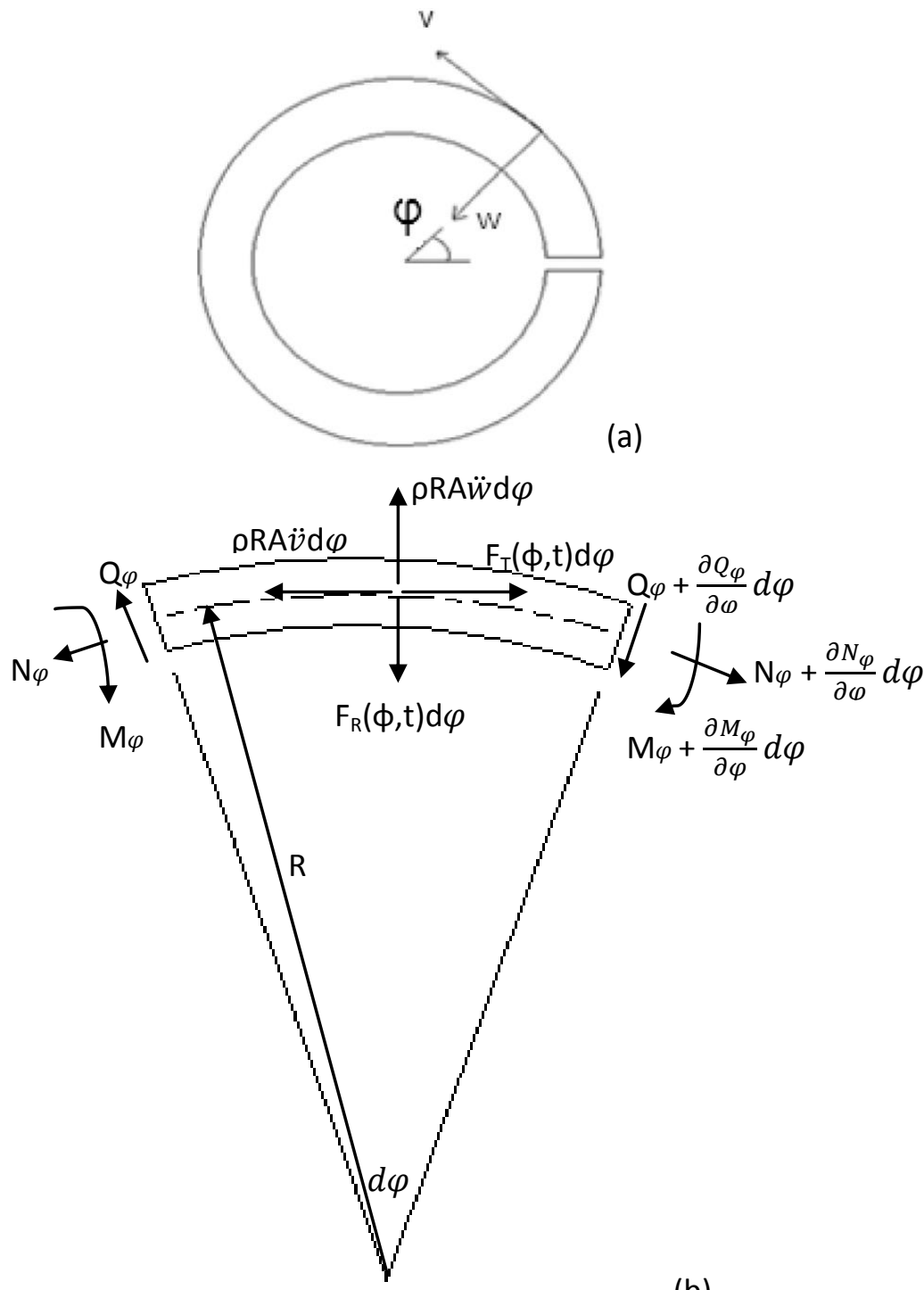

(b)

Figure 2: a) In-plane degrees of freedom of an incomplete ring and

b) Ring segment free body diagram

\subsection{Natural modal frequencies of the ring}

The geometric and material properties of the ring under investigation are listed in Table 1. The ring has a large central radius-to-thickness ratio $(\approx 12.3)$ and the variable $\frac{I}{A R^{2}} \approx 1.24810^{-5} \ll 1$, in accord with the assumption that it is a thin structure (Lang, 1962). The neutral axis is also assumed to be inextensible $\left(\frac{d}{R} \approx 0.0814<0.1\right)$, which is a valid assumption for analysing the ring's forced response when modes lower than the fifth harmonic are only considered as important (Lang, 1962). Therefore, the following relationship couples the tangential and radial displacements: 


$$
w=\frac{\partial v}{\partial \varphi}
$$

\begin{tabular}{|l|l|}
\hline Elastic Modulus, $E$ & $210 \mathrm{GPa}$ \\
\hline Lubricant density, $\rho$ & $7800 \mathrm{~kg} / \mathrm{m}^{3}$ \\
\hline Ring Thickness, $d$ & $3.5 \mathrm{~mm}$ \\
\hline Axial Face-width, $b$ & $1.198 \mathrm{~mm}$ \\
\hline Nominal Ring Radius, $R$ & $43 \mathrm{~mm}$ \\
\hline $\begin{array}{l}\text { Ring cross-section second area } \\
\text { moment of area, I }\end{array}$ & $2.25 \times 10^{-12} \mathrm{~m}^{4}$ \\
\hline $\begin{array}{l}\text { Incomplete ring subtended } \\
\text { angle, } \alpha\end{array}$ & $359^{\circ}$ \\
\hline
\end{tabular}

Table 1: Compression ring and lubricant properties

The free body diagram of a ring segment can be found in Figure $2(b)$, where $Q(\varphi)$ is the transverse force, $\mathrm{N}(\varphi)$ is the circumferential normal force and, $\mathrm{M}(\varphi)$ is the bending moment. Rotary inertia is neglected in this analysis. The remaining force terms $F_{R}$ and $F_{T}$ correspond to the external excitations in the radial and tangential directions, respectively. Therefore, the equations of motion in both the tangential and radial directions are as follows (Lang, 1962):

$$
\begin{gathered}
\frac{\partial^{6} v}{\partial \varphi^{6}}+2 \frac{\partial^{4} v}{\partial \varphi^{4}}+\frac{\partial^{2} v}{\partial \varphi^{2}}+\frac{1}{p \omega_{0}^{2}} \frac{\partial^{4} v}{\partial \varphi^{2} \partial t^{2}}-\frac{1}{p \omega_{0}^{2}} \frac{\partial^{2} v}{\partial t^{2}}=\frac{a^{3}}{E I}\left\{\frac{\partial^{2}}{\partial \varphi^{2}}\left[F_{R}(\varphi, t)\right]-\left[F_{T}(\varphi, t)\right]\right\} \\
\frac{\partial^{6} w}{\partial \varphi^{6}}+2 \frac{\partial^{4} w}{\partial \varphi^{4}}+\frac{\partial^{2} w}{\partial \varphi^{2}}+\frac{1}{p \omega_{0}^{2}} \frac{\partial^{4} w}{\partial \varphi^{2} \partial t^{2}}-\frac{1}{p \omega_{0}^{2}} \frac{\partial^{2} w}{\partial t^{2}}=\frac{a^{3}}{E I}\left\{\frac{\partial^{2}}{\partial \varphi^{2}}\left[F_{R}(\varphi, t)\right]-\frac{\partial}{\partial \varphi}\left[F_{T}(\varphi, t)\right]\right\}
\end{gathered}
$$

It is worth noting that the term $F_{R}$ is the residual radial force obtained from equation (7). The homogeneous parts of equations (9) and (10) have been solved in the past by several authors including Love (1944), Archer (1960) and Ojalvo (1962). The solution forms (known as modal functions) are the same for both $v$ and $w$ degrees of freedom and are dependent on the value of the frequency parameter $\lambda_{n}$ :

If $\lambda_{n}<\lambda_{L}$, then:

$V_{n}=A_{n 1} \cos d_{n} \varphi+A_{n 2} \sin d_{n} \varphi+A_{n 3} \cos e_{n} \varphi+A_{n 4} \sin e_{n} \varphi+A_{n 5} \cos f_{n} \varphi+A_{n 6} \sin f_{n} \varphi$

and:

$$
\begin{array}{r}
W_{n}=-A_{n 1} d_{n} \sin d_{n} \varphi+A_{n 2} \mathrm{~d}_{\mathrm{n}} \cos \mathrm{d}_{\mathrm{n}} \varphi-A_{n 3} e_{n} \sin e_{n} \varphi+A_{n 4} e_{n} \cos e_{n} \varphi \\
-A_{n 5} f_{n} \sin f_{n} \varphi+A_{n 6} f_{n} \cos f_{n} \varphi
\end{array}
$$


If $\lambda_{L}<\lambda_{n}<\lambda_{U}$, then:

$$
\begin{gathered}
V_{n}=A_{n 1} \cos d_{n} \varphi+A_{n 2} \sin d_{n} \varphi+A_{n 3} \cos \mu_{n} \varphi \cosh \delta_{n} \varphi+ \\
A_{n 4} \sin \mu_{n} \varphi \cosh \delta_{n} \varphi+A_{n 5} \cos \mu_{n} \varphi \sinh \delta_{n} \varphi+A_{n 6} \sin \mu_{n} \varphi \sinh \delta_{n} \varphi
\end{gathered}
$$

and:

$$
\begin{gathered}
W_{n}=-d_{n} A_{n 1} \sin d_{n} \varphi+d_{n} A_{n 2} \cos d_{n} \varphi \\
+A_{n 3}\left(-\mu_{n} \sin \mu_{n} \varphi \cosh \delta_{n} \varphi+\delta_{n} \cos \mu_{n} \varphi \sinh \delta_{n} \varphi\right) \\
+A_{n 4}\left(\mu_{n} \cos \mu_{n} \varphi \cosh \delta_{n} \varphi+\delta_{n} \sin \mu_{n} \varphi \sinh \delta_{n} \varphi\right) \\
+A_{n 5}\left(-\mu_{n} \sin \mu_{n} \varphi \sinh \delta_{n} \varphi+\delta_{n} \cos \mu_{n} \varphi \cosh \delta_{n} \varphi\right) \\
+A_{n 6}\left(\mu_{n} \cos \mu_{n} \varphi \sinh \delta_{n} \varphi+\delta_{n} \sin \mu_{n} \varphi \cosh \delta_{n} \varphi\right)
\end{gathered}
$$

If $\lambda_{n}>\lambda_{U}$, then:

$$
V_{n}=A_{n 1} \cos d_{n} \varphi+A_{n 2} \sin d_{n} \varphi+A_{n 3} \cosh e_{n} \varphi+A_{n 4} \sinh e_{n} \varphi+A_{n 5} \cosh f_{n} \varphi+A_{n 6} \sinh f_{n} \varphi
$$

and:

$$
\begin{aligned}
W_{n}=-d_{n} A_{n 1} \sin d_{n} \varphi+d_{n} A_{n 2} \cos d_{n} \varphi+ & e_{n} A_{n 3} \sinh e_{n} \varphi+e_{n} A_{n 4} \cosh e_{n} \varphi \\
& +f_{n} A_{n 5} \sinh f_{n} \varphi+f_{n} A_{n 6} \cosh f_{n} \varphi
\end{aligned}
$$

The condition, where: $\lambda_{n}<\lambda_{L}$, does not arise when considering an incomplete ring, and can only occur when $\alpha>2 \pi$. Limits $\lambda_{U}$ and $\lambda_{L}$ are independent of the ring geometry, and have values of $\lambda_{L}=$ 0.1134 and $\lambda_{U}=17.637$. The value of $\lambda_{n}$ is determined by solving the following characteristic equation:

$$
\sigma_{n}^{6}+2 \sigma_{n}^{4}+\left(1-\lambda_{n}\right) \sigma_{n}^{2}+\lambda_{n}=0
$$

The constants $d_{n}, e_{n}, f_{n}, \delta_{n}$ and $\mu_{n}$ depend on the roots of equation (17), which is a cubic equation in $\sigma^{2}$. The expressions for $V_{n}$ and $W_{n}$ are substituted into the ring boundary conditions (free-free in this case). Therefore, three equations are implemented at the ring ends (for $\varphi=0$ and $\varphi=\alpha$ ):

$$
\frac{d^{2} V_{n}}{d \varphi^{2}}+\frac{d^{4} V_{n}}{d \varphi^{4}}=0
$$




$$
\begin{gathered}
-\xi \frac{d V}{d \varphi}+\frac{d^{3} V_{n}}{d \varphi^{3}}+\frac{d^{5} V_{n}}{d \varphi^{5}}=0 \\
\frac{d V}{d \varphi}+\frac{d^{3} V_{n}}{d \varphi^{3}}=0
\end{gathered}
$$

The above process gives a $6 \times 6$ matrix with respect to the constants $A_{n 1}-A_{n 6}$. The $\lambda_{n}$ values are found when the determinant of this matrix vanishes. The natural frequency (in rad/s) is then given as:

$$
\omega_{n}=\sqrt{\frac{\lambda E I}{m R^{4}}}
$$

\subsection{Orthogonality Condition and Mode Shapes}

The particular solution of equation (9) takes the following form (the solution of equation (10) is determined using the inextensibility condition (8)). Thus:

$$
v(\varphi, t)=\sum_{n=1}^{\infty} V_{n}(\varphi) \xi_{n}(t)
$$

In order to determine the $A_{n}$ coefficients, the orthogonality condition of the ring modal functions must be imposed, thus:

$$
\begin{aligned}
& \int_{0}^{\alpha} \rho R A\left(V_{i} V_{j}+W_{i} W_{j}\right) d \varphi=0, \quad i \neq j \\
& \int_{0}^{\alpha} \rho R A\left(V^{2}+W^{2}\right) d \varphi=1, \quad i=j
\end{aligned}
$$

where $i$ and $j$ represent different mode numbers. The boundary conditions are used to obtain expressions for $A_{n 1}-A_{n 5}$ with respect to $A_{n 6}$. These are substituted into equation (24), which is solved for $A_{n 6}$. Hence, the remaining constants can be calculated, allowing the determination of the corresponding mode shape at each natural frequency.

\subsection{Forced Response}

The time varying term of equation (22), $\xi_{n}(t)$, is determined through solution of (Lang, 1962):

$$
\ddot{\xi}_{n}+\omega_{n}^{2} \xi_{n}=Q_{n}(t)
$$


where:

$$
Q_{n}(t)=-\frac{\int_{0}^{\alpha} V_{n}\left\{\frac{\partial}{\partial \varphi} F_{R}(\varphi, t)-F_{T}(\varphi, t)\right\} d \varphi}{\rho a A \int_{0}^{\alpha}\left(W_{n}^{2}+V_{n}^{2}\right) d \varphi}
$$

Equation (25) is derived from equation (9) after substitution of the particular solution (22), rearranging the result and applying the orthogonality condition (Lang, 1962). Neglecting any damping effects, the solution of equation (25) is obtained analytically as:

$$
\xi_{n}(t)=\frac{1}{\omega_{n}} \int_{0}^{t} Q_{n}\left(\tau^{\prime}\right) \sin \omega_{n}\left(t-\tau^{\prime}\right) d \tau^{\prime}+C_{n 1} \sin \omega_{n} t+C_{n 2} \cos \omega_{n} t
$$

The coefficients $C_{n 1}$ and $C_{n 2}$ are determined from the initial conditions. The radial force in equation (26) must be differentiable in $\varphi$, which is a necessary condition for not exciting the extensional modes as stated by Lang (1962). Equations (20) and (8) are used to give the tangential and radial deflection at each ring location. This is repeated for each time step (ring position, i.e. crank angle), until the desired time period is completed. The solution process comprises the following steps:

1. Initial conditions and ring properties are defined.

2. The first solution form, valid for $\left(\lambda_{L}<\lambda_{n}<\lambda_{U}\right)$ as described by equations (9) and (10), is used to find the eigenvalues within this range. The case $\left(\lambda_{n}<\lambda_{L}\right)$ only occurs when $\alpha>2 \pi$ (Archer, 1960), and so is not applicable to this problem.

3. Expressions for the normal force, shear force and bending moment at each end of the ring are formed using equations 18-20. These represent the boundary conditions, giving 6 equations expressed in terms of constants $A_{n 1}-A_{n 6}$. A $6 \times 6$ matrix can, therefore, be formed. The determinant of this matrix is set to zero and $\lambda_{n}$ is calculated, leading to the natural frequency.

4. The orthogonality conditions of the ring modal functions $\left(V_{n}\right.$ and $\left.W_{n}\right)$ are applied to calculate constants $A_{n 1}-A_{n 6}$. Using the boundary conditions, expressions for $A_{n 1}-A_{n 5}$ in terms of $A_{n 6}$ are formed. Substitution into equation (24) and solving for $A_{n 6}$ leads to calculation of the modal constants, giving the mode shape at natural frequency $n$.

5. For the first time step, equations (26) and (27) are solved, where $F_{R}$ and $F_{T}$ are external forcing terms. The response at each point circumferentially around the ring is then calculated.

6. The time step is advanced and step 5 is repeated.

7. After the entire time interval has elapsed, the response for the next mode is required. Steps 4-8 are repeated until there are no more valid solutions for the case $\left(\lambda_{L}<\lambda_{n}<\lambda_{U}\right)$. When this 
is the case, the next solution form $\left(\lambda_{n}>\lambda_{U}\right)$ is used, and the whole solution process is repeated.

8. Once the response for each mode has been calculated, these are all added together, giving the total response for the given number of modes.

\section{Results}

\subsection{Validation Method}

The predictions of the analytical eigenvalue problem for the ring in-plane dynamics are compared with those of a finite element model developed in the commercial code PATRAN/NASTRAN. The FEA model comprises 810 quadrilateral elements with 1024 nodes, each with 6 degrees of freedom and assuming free-free boundary conditions. First, the natural frequencies and mode shapes are compared (Table 2). Very good agreement is noted, with only deviations exceeding $1 \%$ for the higher ring modes. Figure 3 shows a comparison between the corresponding mode shapes. Again, good agreement is found.

\begin{tabular}{|c|c|c|c|}
\hline $\begin{array}{c}\text { Mode } \\
\text { Number }\end{array}$ & $\begin{array}{c}\text { Analytical Method } \\
\text { Natural Frequency (Hz) }\end{array}$ & $\begin{array}{c}\text { FEA model } \\
\text { Natural Frequency (Hz) }\end{array}$ & \% Difference \\
\hline 1 & 198.44 & 198.31 & 0.066 \\
\hline 2 & 432.8 & 432.35 & 0.104 \\
\hline 3 & 972.06 & 969.76 & 0.237 \\
\hline 4 & 1803.24 & 1795.40 & 0.437 \\
\hline 5 & 2892.18 & 2871.90 & 0.706 \\
\hline 6 & 4224.74 & 4181.70 & 1.029 \\
\hline 7 & 5793.44 & 5712.80 & 1.412 \\
\hline
\end{tabular}

Table 2: Natural frequencies obtained analytically and using FEA

Then, a harmonic excitation $F_{R}(\varphi, t)$ was applied radially to the ring. This force varies both spatially, as well as temporally:

$$
F_{R}(\varphi, t)=F_{R \max } * \sin 2 \varphi * \sin \omega_{f} t
$$

For simplicity no tangential excitation $F_{T}(\varphi, t)$ is considered. 

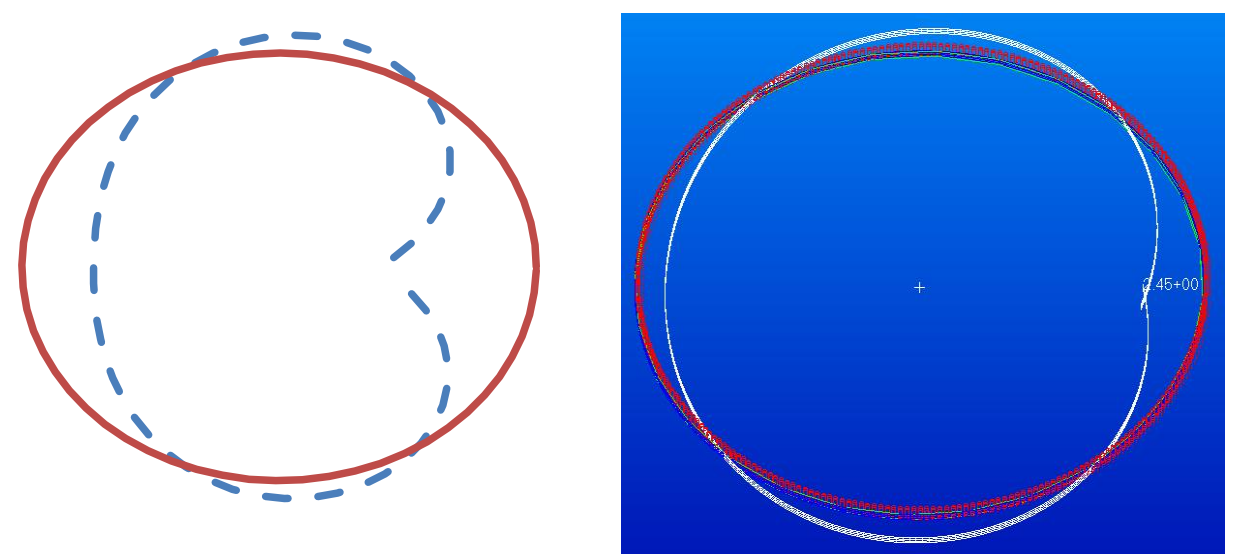

Figure 3: Mode shape comparison (a) Analytical $(f=972.06 \mathrm{~Hz})$ and $(b) F E A(f=969.76 \mathrm{~Hz})$

Figure 4 shows the response time history of the radial displacement, $w$ at a location opposite to the incomplete ring's end. The excitation frequency of $300 \mathrm{~Hz}$ was chosen in order to remain away from any of the ring's natural frequencies and avoid resonance. $F_{R \max }$ is calculated by applying a $1 \mathrm{kPa}$ pressure to the ring. There is good agreement between the analytical and FEA predictions (Figure 4), as ascertained through the maximum amplitudes obtained.

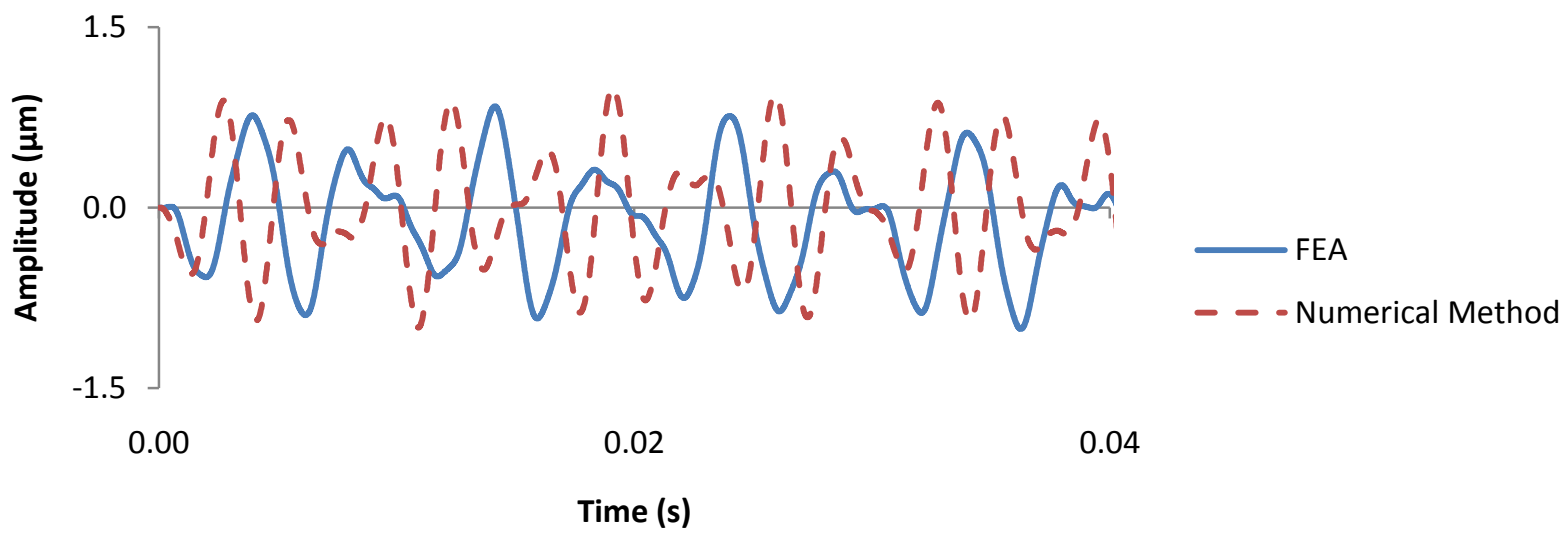

Figure 4: Radial displacement time histories for both methods

Frequency analysis was performed on the dynamic response data of Figure 4. The comparison between the Fast Fourier Transform (FFT) results of the analytical method and that of the FEA is shown in Figure 5. Again, the agreement is very good. 

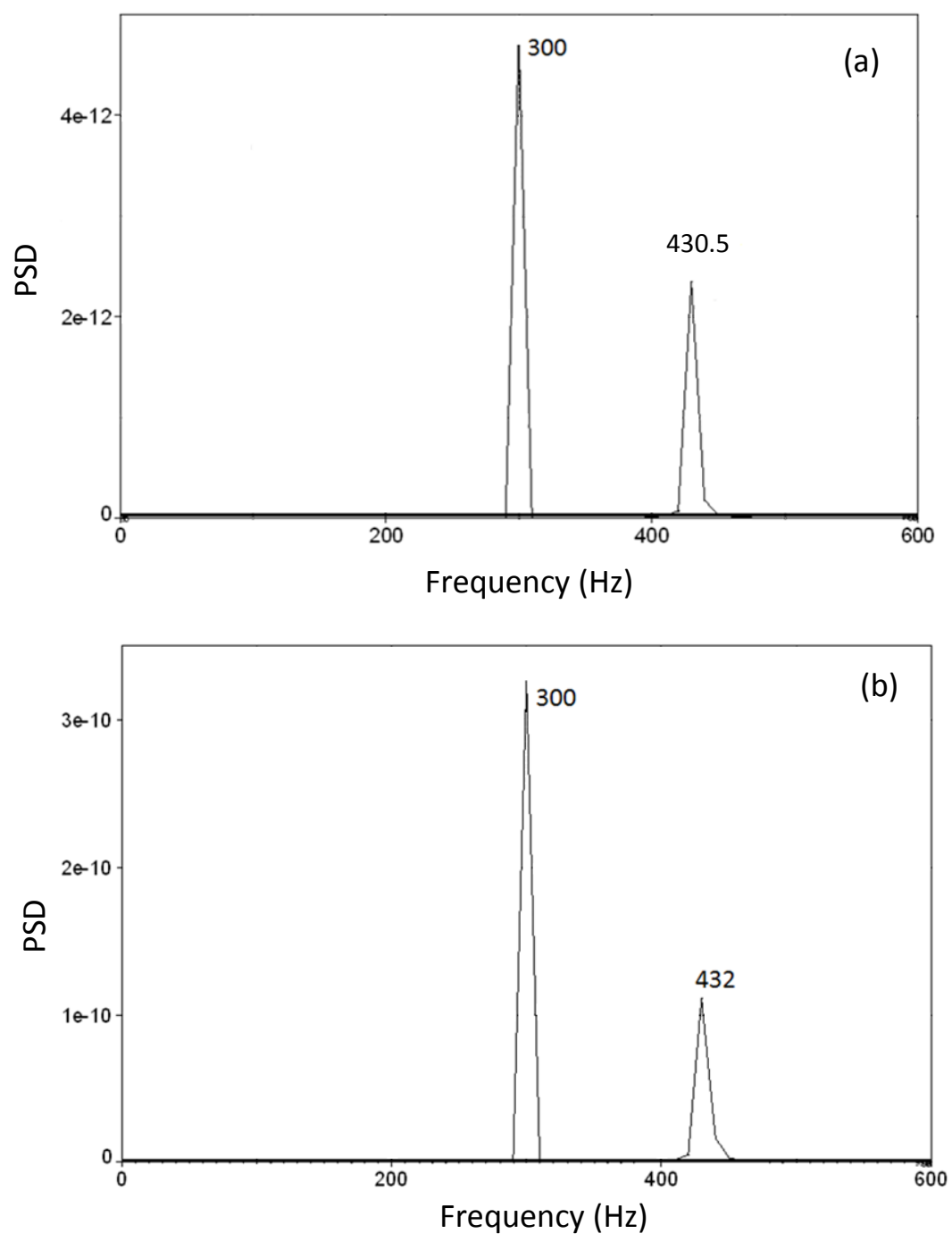

Figure 5: Spectra of the radial dynamic response a) FEA method and b) Analytical method

\subsection{Effect of ring dynamics on tribological performance}

The validated analytical ring dynamic model is used within the ring-bore tribological study. Ring conformability to the bore is assumed, as well as isothermal contact condition. The region of particular interest is in transition from compression to the power stroke in the 4-stroke process. This is because at the reversal, cessation of lubricant entrainment into the contact results in greater contribution of boundary friction (increased direct surface interactions) (Ma et al, 1997, Akalin and Newaz, 2001, Balakrishnan and Rahnejat, 2004, Mishra et al, 2009). At maximum pressure (firing point) there is a significant contact force. This corresponds to the highest net applied force, causing ring's dynamic behaviour. Figure 6 shows the force profile at the crank angle corresponding to $3^{\circ}$ past the Top Dead Centre (TDC), with an engine speed of 2000rpm. The shape of the force profile is considered to be constant for every crank angle interval investigated. 


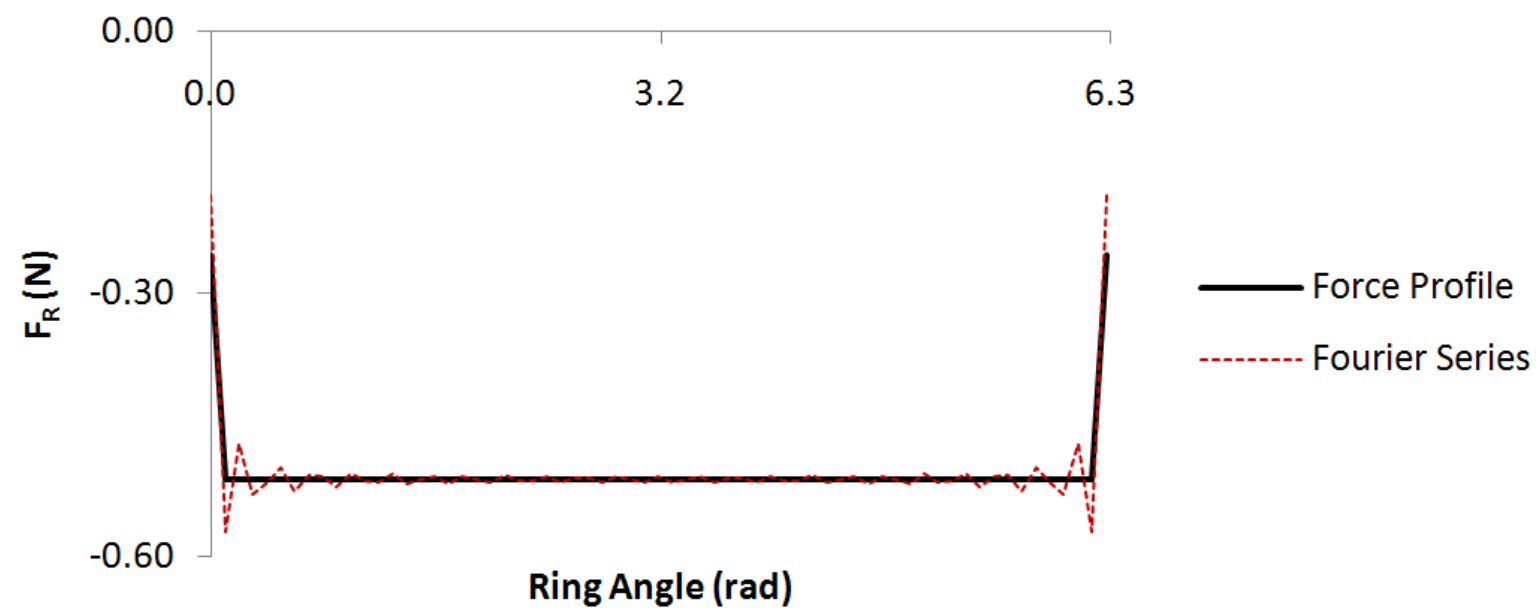

Figure 6: Force Profile at $3^{\circ}$ past TDC (engine speed of 2000rpm)

The force profile data is expressed in a Fourier series as:

$$
F_{R}(\varphi)=A_{0}+\sum_{k=1}^{n}\left[A_{k} \cos (k \varphi)+B_{k} \sin (k \varphi)\right]
$$

Representing the applied radial force in this manner is compatible with the analytical method for the evaluation of forced response. The integration time corresponds to $1^{\circ}$ crank angle advance, for a known engine speed (2000 rpm in this case): $\Delta t=1 /\left(\frac{2000 \times 360}{60}\right)$. The integration time is sub-divided into 50 steps for the ring dynamic analysis, with the resulting response time history of the ring evaluated. The gas pressure profile for the 2000rpm engine speed is shown in figure 7(a). The inset to the figure indicated by (b) shows the crank angle range of interest in the current study (transition from the compression to the power stroke, extending just beyond the firing point). 


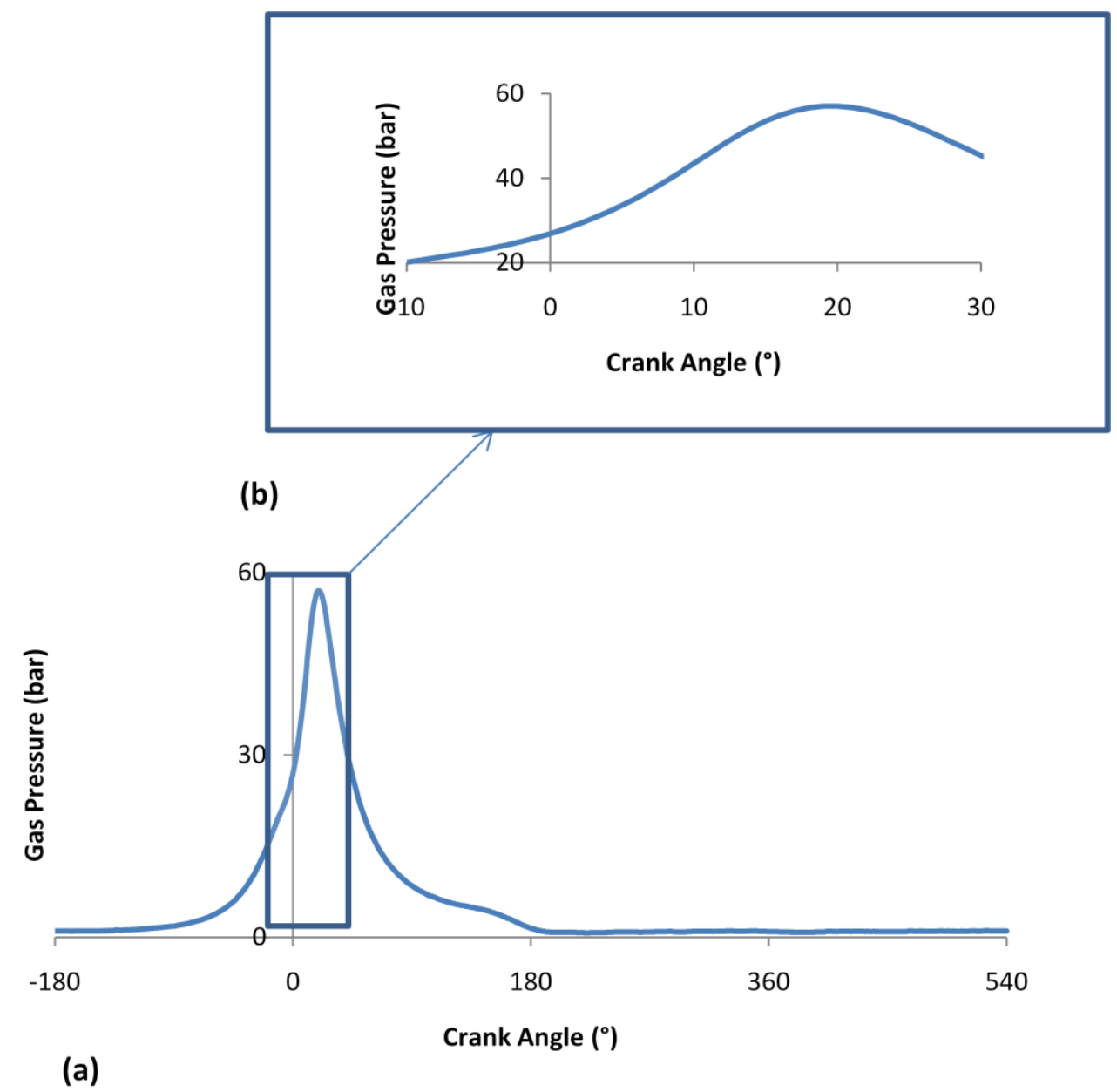

Figure 7: (a) Gas pressure profile throughout the four-stroke engine cycle and (b) area of particular interest (engine speed $=2000 \mathrm{rpm}$ )

Figures 8(a)-(f) show the film thickness variation around the ring-bore periphery (elastic film shape) at various crank angle intervals. These show deviations from a gap between a rigid ring and the bore surface (rigid film shape). The figure also shows the deformed unwrapped shape of the ring (global deformation). Two important observations are made. Firstly, an elastic ring does not conform to the bore surface, an idealised assumption which is often made to warrant one dimensional analysis of the ring-bore conjunction (along the ring face-width). Secondly, it also shows that static conformability analysis, often used to determine the ring-bore gap in two-dimensional tribological studies (e.g. Hill and Newman, 1985 and Tomanik, 1996), is idealised and does not include the transient behaviour of the ring. The results shown in figures $8(a)-(f)$ indicate an increase in the gap between the ring and the bore at most points around the ring periphery, except for a small segment where the film thickness occurs. As the forces applied in this study were acting radially inwards on the compression ring, this increase in gap is to be expected. This result can be interpreted as a loss of conformability between the ring and bore, which may result in blow-by and loss of power. 


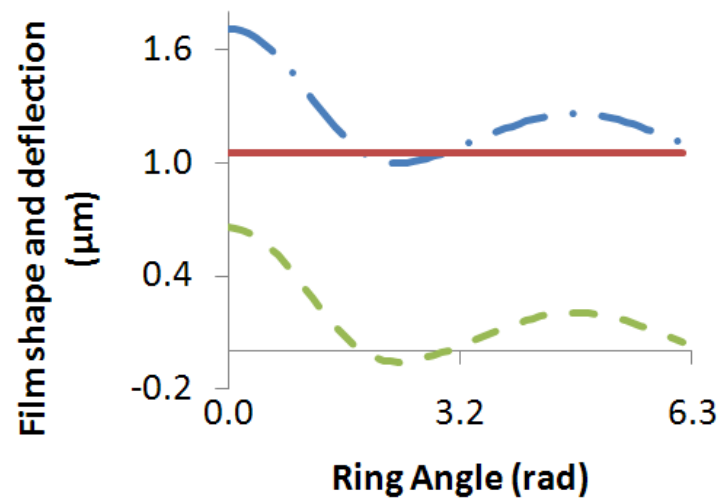

(a): $3^{\circ}$ before TDC

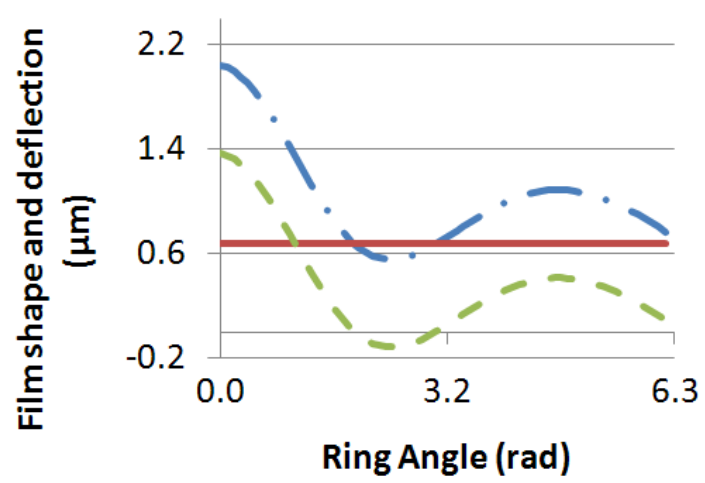

(c): $3^{\circ}$ past TDC

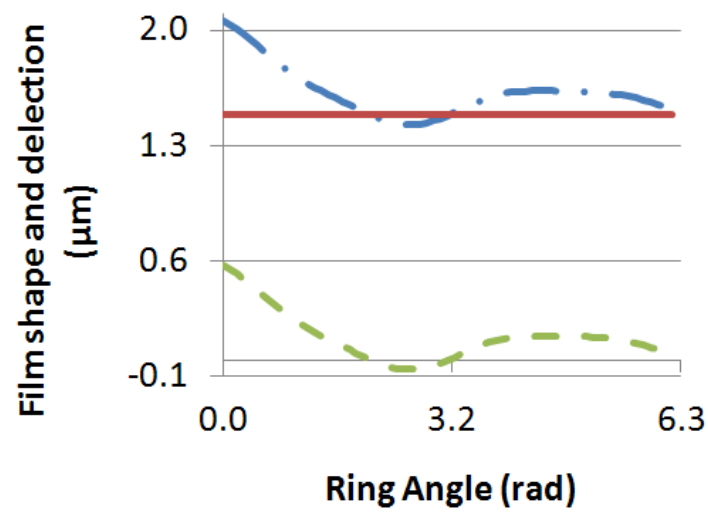

(e): $20^{\circ}$ past TDC, firing point

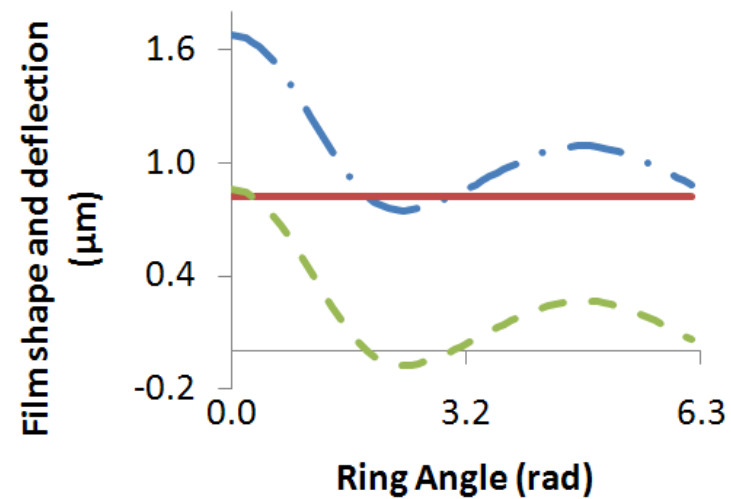

(b): TDC

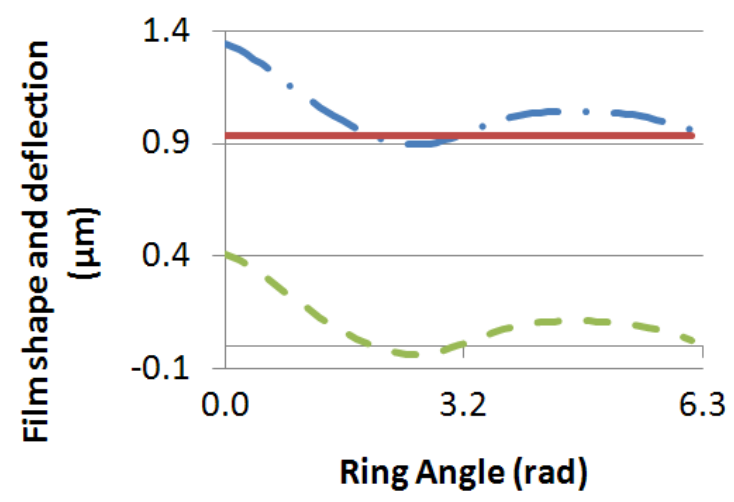

(d): $10^{\circ}$ past TDC

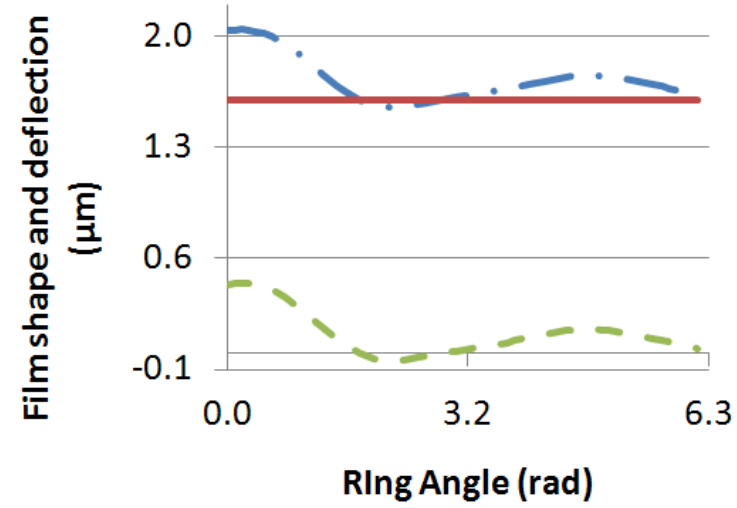

(f): $22^{\circ}$ past TDC

Figure 8: Film profile and ring deflection at various crank angle intervals around the TDC and firing point (engine speed $=2000 \mathrm{rpm}$ ). elastic film shape

Minimum film thickness occurs during the reversal; in the region $-3^{\circ} \leq \theta \leq 3^{\circ}, \theta$ being the crank angle. Film thickness of order of $0.5-1 \mu \mathrm{m}$ is predicted, giving rise to a mixed regime of lubrication with the Stribeck's oil film parameter; $\lambda_{s}<3$. 
The globally deformed shapes of the ring in figures $8(a)-(f)$ are transitory, because there is insufficient time for the ring to reach its steady state response. Figure $9(b)$ is an unwrapped representation of the steady state ring shape at $3^{\circ}$ past the TDC. This corresponds to the usual static conformability analysis (Hill and Newman, 1985, Mishra et al, 2008). It can be seen that the resulting deformation is largely dominated by the first ring mode shape $(f=198.4 \mathrm{~Hz}$ ) (figure $9(c)$ ). The difference between this steady state shape and the actual transient elastic film shape in transit (figure 9(a)) is not only a function of the net applied force $F_{R}$, but also the engine speed. Therefore, a given ring would behave quite differently, not only through the engine cycle, but also at different engine speeds. This means that friction and oil consumption are functions of ring elasticity as much as ring-bore conjunctional geometry, topography and kinematics, a fact that is often ignored in most analyses.

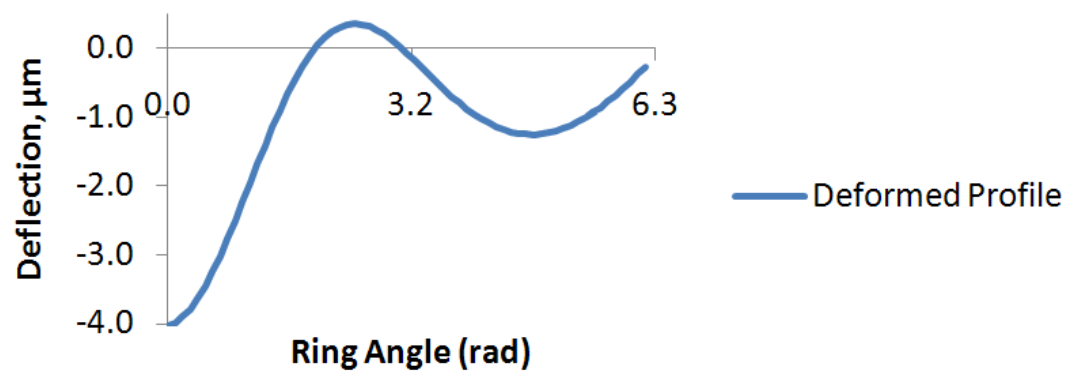

(a)

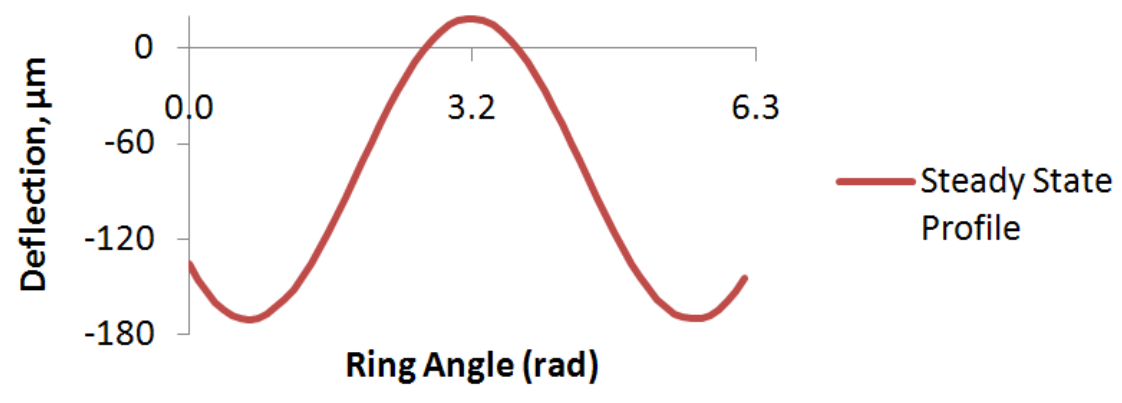

(b) 


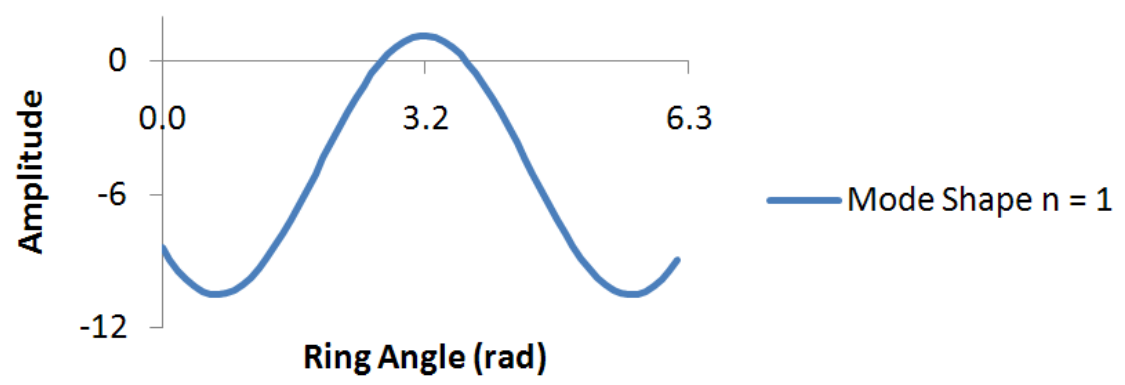

(c)

Figure 9: (a) Deformed transient profile $3^{\circ}$ past TDC, b) Steady state response at $3^{\circ}$ past TDC and (c) First in-plane ring mode shape

The power spectral density of the transient response of figure 9(a) is shown in figure 10(a). The power spectrum shows the dominance of the first modal response of the ring with small contributions from its second and third modes. In fact, only the first three modal responses are noted throughout the engine cycle as shown, for example in figure 10(b). An analysis including the first 7 ring modes does not alter the results.

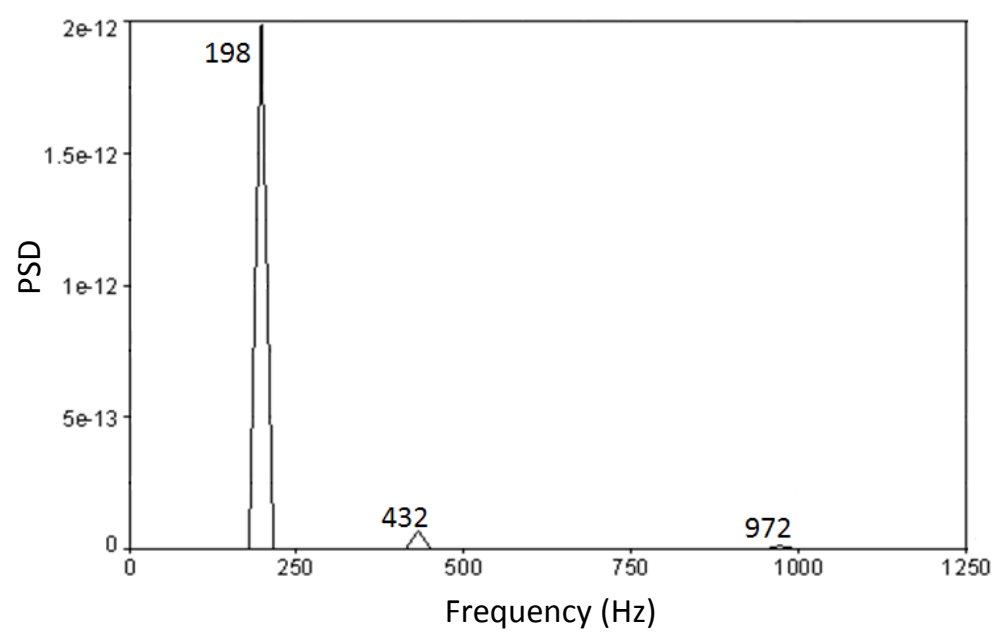

(a)- Spectral content of the transient response of figure 9(a)

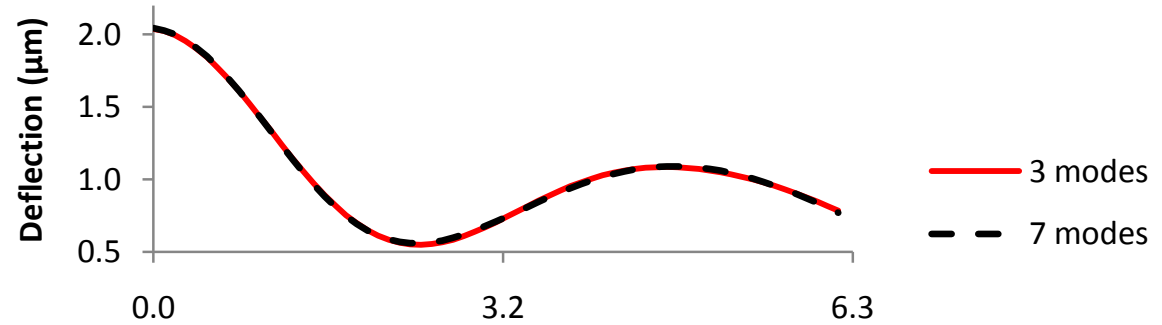

Ring Angle (rad) 
(b)- The insignificant contribution of higher order modes in the ring dynamics

Figure 10: Features of the ring transient response

With the incorporation of ring modal behaviour within a tribological model of ring-bore conjunction, it is important to ascertain the influence of ring behaviour upon friction. Significant contribution to friction occurs at the top dead centre reversal in transition from compression to power stroke, extending just beyond the firing point (at $20^{\circ}$ crank angle position for the engine under consideration). This is generally the case for most engines as reported by Furuhama and Sasaki (1983), Ma et al (1997), Akalin and Newaz (2001), Bolander et al (2005) and Mishra et al (2009). To make a realistic assessment of friction an analysis under mixed regime of lubrication is required. Such a model was presented by Greenwood and Tripp (1971) and has been used in a number of studies, including some of those noted above. Thus:

$$
f=f_{v}+f_{a}
$$

where the viscous friction is obtained as $f_{v}=\tau A_{c}$, if $\lambda_{s} \geq 3$ (fluid film lubrication). Also, the viscous shear stress is: $\tau= \pm \frac{h}{2} \frac{d p}{d x}+\frac{\eta \Delta U}{h}$. If, on the other hand, $\lambda_{s}<3$, then the regime of lubrication is mixed and the viscous and boundary contributions are obtained as:

$$
f_{v}=\tau\left(A_{c}-A_{a}\right)
$$

where the asperity interaction area is calculated as:

$$
A_{a}=\pi^{2}\left(\zeta \kappa \sigma_{R M S}\right)^{2} \sqrt{\frac{\sigma_{R M S}}{\kappa}} A_{c} F_{2}\left(\lambda_{s}\right)
$$

where, $F_{2}\left(\lambda_{s}\right)$ is another Gaussian statistical function similar to $F_{5 / 2}\left(\lambda_{s}\right)$, this time representative of the boundary friction area of the opposing asperity tips. These functions are provided with polynomial fits by Teodorescu et al (2005). $A_{C}$ is the apparent contact area of the ring outer periphery, in contact with the bore surface. The contact of wetted asperity tips is considered to be in non-Newtonian shear at the Eyring shear stress of the lubricant, thus the boundary friction is:

$$
f_{b}=\tau_{0} A_{a}+\xi W_{a}
$$


where: $\xi$ is the boundary shear strength of the contacting surfaces; $\xi=0.17$ for ferrous-based materials (Teodorescu et al, 2005).

Figure 11 shows the variation of friction for both a rigid and an elastic ring during the piston reversal at the top dead centre (i.e. $0^{\circ}$ crank angle position) and beyond the point of cylinder firing at $20^{\circ}$ crank angle position. This is the transition from the compression to the power stroke, where it has already been noted that the main contribution to friction by the compression ring occurs. For sake of clarity the variation in the region (a): $-3^{\circ} \leq \theta \leq 3^{\circ}$ corresponding to the reversal and that through the high pressure region (b): $10^{\circ} \leq \theta \leq 22^{\circ}$ are shown separately. The loss of conformability predicted in figures $8(\mathrm{a})-(\mathrm{f})$ results in a reduction in total friction calculated in the investigated regions. The compression ring has deformed, meaning a larger ring-bore gap exists for the majority of the ring's circumference.

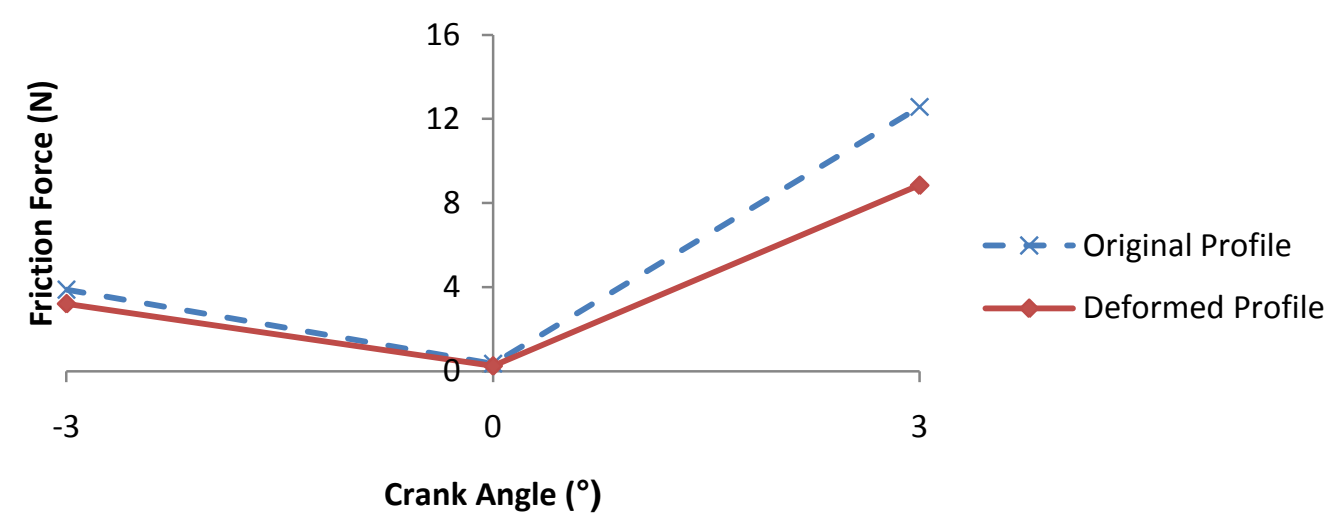

(a)- Transition in reversal at the top dead centre

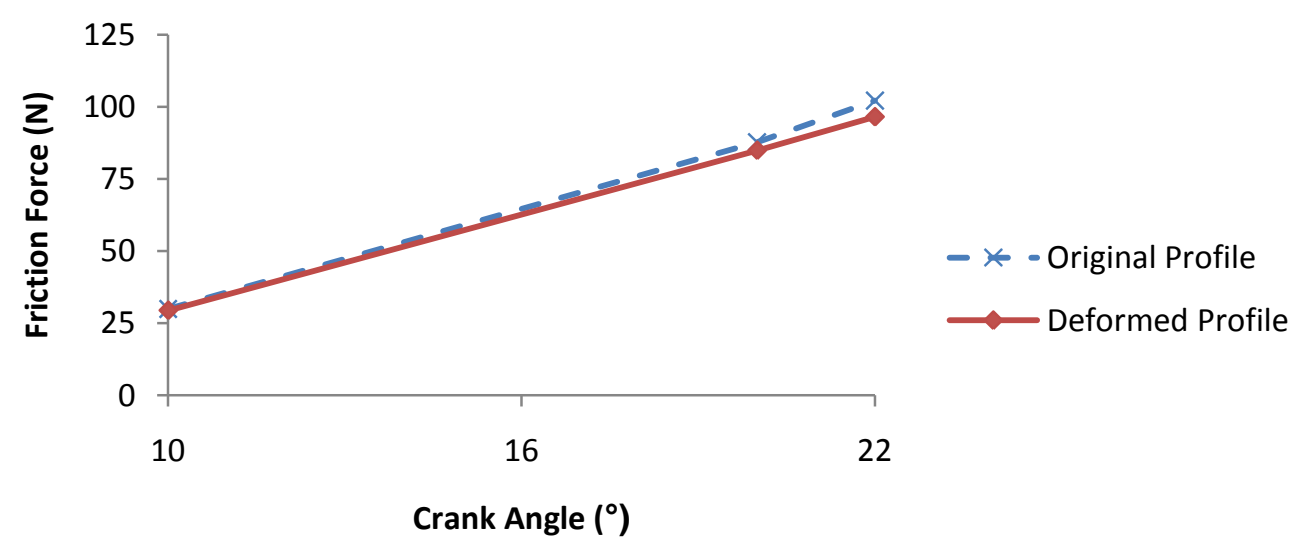

(b)- Transition through maximum combustion pressure

Figure 1: Prediction of friction for a rigid and an elastic compression ring 


\section{4- Conclusions}

The elastic ring modal behaviour is more in line with practice as one of the functions of the designed ring is to guard against the transport of combustion gasses into the lower part of the engine. This requirement is essential, but has clearly the disadvantage of increased boundary interactions. A significant finding of the current analysis is that whilst the ring modal behaviour caters for this requirement, its longer settling time guards against complete conformance to an idealised right circular cylinder which would otherwise result in excessive friction. Of course in reality the bore is not an ideal right circular cylinder and a more detailed analysis including the effect of bore out-ofroundness would also be required. The non-conformance of the ring to the bore surface also results in emerging clearances which can contribute to blow-by gasses and thus emission levels. However, modern engines recirculate any blow-by gasses back into the intake system. Nevertheless, blowby gasses can cause oil dilution and contamination. The predictions in this study show that ring modal behaviour may increase the chance of blow-by due to internal forces deforming the compression ring from its idealised circular shape. However, the minimum film thickness is also reduced, which may increase friction and wear in a localised manner. Whilst friction is a source of parasitic losses, a certain degree of ring friction is essential in order to guard against the axial inertial motion of the ring known as ring flutter. An excessive amount of friction can also promote ring twist. Hence, there is potentially a link between the ring in-plane modal behaviour and its out-of-plane motions through friction. This means that a more comprehensive analysis would be necessary with all forces and moments included, such as those shown in figure 1. Coupled with a tribological study of the contact, such an analysis would be very computationally intensive and thus the analytical ring dynamic model as opposed to a numerical solution (for example based on FEA) would reduce the complexity of the computations.

\section{5- Acknowledgements}

The authors wish to express their gratitude to Engineering and Physical Sciences Research Council (EPSRC) for the funding extended to the Encyclopaedic Program Grant (www.Encyclopaedic.org), under which this research is carried out in collaboration with a consortium of industry and academic institutions. In particular, the authors acknowledge the financial and technical support of Aston Martin Lagonda. 


\section{6- References}

Akalin, O. and Newaz, G. M., "Piston ring cylinder bore friction modelling in mixed lubrication regime. Part I: analytical results", Trans. ASME, J. Trib., 123, pp.211-218, 2001

Almqvist, T. and Larsson, R., "The Navier-Stokes approach for thermal EHL line contact solutions", Trib. Int., 35, pp. 163-170, 2002

Andersson, B.S., "Company's perspective in vehicle tribology", Proc. $18^{\text {th }}$ Leeds-Lyon Sympos., Dowson, D., Taylor, C.M. and Godet, M. (Eds.), Elsevier, pp. 503-506, 1991

Antman, S. and Warner, W. H., "Dynamic Stability of Circular Rods", J. Soc. Indust. Appl. Math., 13, pp. 1007-1018, 1965

Archer, R. R, "Small Vibrations of Thin Incomplete Circular Rings", Int. J. Mech. Sci., 1, pp. 45-56, 1960 Auciello, N. M., De Rosa, M. A., "Free Vibrations of Circular Arches: A Review", J. Sound and Vibration, 176, pp. 433-458, 1994

Balakrishnan, S. and Rahnejat, H. "Isothermal transient analysis of piston skirt-to-cylinder wall contacts under combined axial, lateral and tilting motion", J. Phys. D: Appl. Phys. 38, 787, 2005

Baker, C. E., Rahmani, R., Theodossiades, S., Rahnejat, H. and Fitzsimons, B., "Thermoelastohydrodynamics of a rough piston compression ring-to-cylinder bore conjunction", Proc. STLE $66^{\text {th }}$ Annual Conf., Atlanta, USA, 2011

Bolander, N. W., Steenwyk, B. D., Sadeghi, F., and Gerber, G. R., "Lubrication regime transitions at the piston ring-cylinder liner interface", Proc. Instn. Mech. Engrs., Part J: J. Engng. Trib., 129, pp. 1931,2005

Brown, F. H, "Lateral Vibration of Ring Shaped Frames", J. Franklin Inst., 217, pp. 41-48, 1934

Chen, S., "In-plane Vibration of Continuous Curved Beams", Nuclear Eng. \& Des., 25, pp. 413-431, 1973

Chong, W.W.F., Teodorescu, M. and Vaughan, N.D., "Cavitation induced starvation for pistonring/liner tribological conjunction", Trib. Int., 44, pp. 483-497, 2010

D'Agostino, V. and Senatore, A., "Fundamentals of lubrication and friction of piston ring contact" in Rahnejat, H. (Ed.) Tribology and dynamics of engine and powertrain, Woodhead Publications, Cambridge, UK, 2010

Den Hartog, J.P, "The Lowest Natural Frequency of Circular Arcs", Phil. Mag., 5, pp. 400-408, 1928

Dowson, D., Ruddy, B.L., Economou, P.N. "The Elastohydrodynamic Lubrication of Piston Rings", Proc. Roy. Soc. Lond. A, 386, pp. 409-430, 1983

Furuhama, S. and Sasaki, S., "New device for the measurement of piston frictional forces in small engines", SAE Tech. Pap. 831284, 1983 
Gardner, T. G., Bert, C. W., "Vibration of Shear Deformable Rings: Theory and Experiment", J. Sound and Vibration, 103, pp. 549-565, 1985

Ghosh, M.K. and Gupta, K., "Thermal Effect in Hydrodynamic Lubrication of Line Contacts Piezoviscous Effect Neglected", Int. J. Mech. Sci., 40, pp. 603-616, 1998

Greenwood, J. A. and Tripp, J. H., "The contact of two nominally at rough surfaces", Proc. Instn Mech. Engrs, Part C: J. Mech. Engng. Sci., 185, pp. 625-633, 1971

Hamilton, G. M., Moore, S. L., "Measurement of the Oil-Film Thickness Between the Piston Rings and Liner of a Small Diesel Engine", Proc. Instn. Mech. Engrs, Part C: J. Mech. Engng. Sci., 188, pp. 253261, 1974

Hill, S.H. and Newman, B.A., "Piston ring designs for reduced friction", SAE Paper No. 841222, 1985

Johnson, K. L., "Regimes of Elastohydrodynamic Lubrication", Proc. Instn. Mech. Engrs., Part C: J. Mech. Engng. Sci., 184, pp. 9-16, 1970

Kang, K. J., Bert, C. W. and Striz, A. G., "Vibration and Buckling Analysis of Circular Arches Using DQM" Computers \& Structures, 60, pp. 49-57, 1996

King, J., 'The King Review of low carbon cars Part I: the potential for CO2 reduction', HMSO, October 2007

Knoll, G., Peekan, H., Lechtape-Grüter, R. and Lang, J., "Computer-Aided Simulation of Piston and Piston Ring Dynamics", Trans. ASME, J. Eng Gas Turbines \& Power, 118, pp. 880-886, 1996

Lamb, H, "On the Flexure and Vibrations of a Curved Bar", Proc. Lond. Math. Soc., 19, pp 365-376, 1888

Lang, T. E, "Vibration of Thin Circular Rings, Part 1", Jet Propulsion Laboratory Technical Report No. 32-261, 1962

Love, A. E. H., "A Treatise on Mathematical Theory of Elasticity", Dover Publications, New York, 1944 Ma, M.T., Sherrington, I., Smith, E.H., "Analysis of Lubrication and Friction for a Complete Piston-Ring Pack with an Improved Oil Availability Model Part 1: Circumferentially Uniform Film", Proc. Instn. Mech. Engrs., Part J: J. Engng. Trib., 211, pp. 1-15, 1997

Mishra, P.C., Balakrishnan, S. and Rahnejat, H., "Tribology of compression ring-to-cylinder contact at reversal", Proc. Instn. Mech. Engrs., Part J: J. Engng. Trib., 222, pp. 815-826, 2008

Mishra, P.C., Rahnejat, H. and King, P.D, "Tribology of the Ring-Bore Conjunction Subject to a Mixed Regime of Lubrication", Proc. Instn. Mech. Engrs., Part C: J. Mech. Engng. Sci., 223, pp. 987-998, 2009 Morley, L. S. D., "The Flexural Vibrations of a Cut Thin Ring", Quart. J. Mech. And App. Maths, 11, pp. 491-497, 1958

Ojalvo, I.U., "Coupled Twist-Bending Vibrations of Incomplete Elastic Rings", Int. J. Mech. Sci., 4, 1962, pp. 53-72 
Piao, Y. and Gulwadi, S. D., "Numerical Investigation of the Effects of Axial Cylinder Bore Profiles on Piston Ring Radial Dynamics", Trans. ASME, J. Eng Gas Turbines \& Power, 125, pp. 1081-1089, 2003

Priest, M. and Taylor, C. M., "Automobile engine tribology - approaching the surface", Wear, 241, pp. 193-203, 2000

Spencer, A., Almqvist, A. and Larsson, R., "A semi-deterministic texture-roughness model of the piston ring-cylinder liner contact", Proc. Instn. Mech. Engrs., Part J: J. Eng. Trib., DOI 10.1177/1350650110396279, 2011

Teodorescu, M., Balakrishnan, S. and Rahnejat, H., "Integrated tribological analysis within a multiphysics approach to system dynamics", Tribology and Interface Engineering Series (Elsevier), 48, pp.725-737, 2005

Tian, T., "Dynamic Behaviour of Piston Rings and their Practical Impact Part 2: Oil Transport, Friction and Wear of Ring/Liner Interface and the Effects of Piston and Ring Dynamics", Proc. Instn. Mech. Engrs., Part J: . Engng. Trib., 216, pp 229-247, 2002

Tian, T., Noordzij, L. B., Wong, V. W. and Heywood, J. B., "Modelling Piston-Ring Dynamics, Blowby, and Ring-Twist Effects", Trans. ASME, J. Eng Gas Turbines \& Power, 120, pp. 843-854, 1998

Timoshenko, S. and Goodier, J.N., Theory of Elasticity, 2nd Ed., McGraw-Hill, Inc., USA, 1951

Tomanik, E., "Piston ring conformability in a distorted bore", SAE Paper No. 960356, 1996

Volterra, E. and Morell, J. D, "Lowest Natural Frequency of Elastic Arc for Vibrations outside the Plane of Initial Curvature", Trans. ASME, J. App. Mech., 28, pp. 624-627, 1961 